\title{
Analysis of Marketing Potential of Bioactive Flour Products for School Meals
}

\author{
Alekseeva T.V.* \\ Service and Restaurant Business Department \\ Voronezh State University of Engineering Technologies \\ Voronezh, Russia \\ e-mail: zyablova@mail.ru
}

Cheremucskina I.V. Department of Trade and Commodity Voronezh State University of Engineering Technologies Voronezh, Russia e-mail: irinacher2010@yandex.ru

\section{Malakova L.V.}

Service and Restaurant Business Department Voronezh State University of Engineering Technologies Voronezh, Russian Federation e-mail: mix_box3@mail.ru

\author{
Agaeva N.Y. \\ Department of Tourism and Hospitality \\ Voronezh State University of Engineering Technologies \\ Voronezh, Russia \\ e-mail: nadinn_ktn@mail.ru \\ Vasilenko I.N. \\ Department of Management, Organization of Production \\ and Industrial Economics \\ Voronezh, Russia \\ e-mail: vasilenkoirina@yandex.ru
}

\section{Zdorovcev E.O.} \\ Service and Restaurant Business Department \\ Voronezh State University of Engineering Technologies \\ Voronezh, Russian Federation \\ e-mail: aune97@mail.ru
}

\begin{abstract}
A study was conducted to determine the preferences of 14-16 years old adolescents when visiting catering points in schools. The purpose of the research was to analyze the marketing potential of flour products with a bioactive additive for feeding schoolchildren of adolescence, identifying the causes of violations of their diet. The study program included questionnaires conducted after the informed consent of the parents or guardians. The questionnaire developed by us included 3 blocks of 5 questions. The first block contained questions designed to disclose information about the diet of schoolchildren aged 14-16 and their attitude to school nutrition. The second block contained questions about the volume and composition of food consumed by respondents during the day. The answers to the questions of the third block made it possible to give a tentative assessment of the demand for flour products of a functional orientation for the analyzed circle of people. After the survey, statistical data processing was carried out. It was found that modern adolescents prefer carbohydrate snacks; they are sorely lacking vitamins, macro-micronutrients, amino acids, polyunsaturated fatty acids and other nutritional food factors, the suppliers of which are bioactive components of animal and plant origin. We have proposed a component composition of a functional additive for the fortification of flour products, consisting of cake of wheat germ, animal albumin and alfalfa seeds. The research results showed that the use of an enriching additive for the production of bioactive flour products for school meals is cost-effective. Summarizing the data obtained during the study, we can conclude: because of their age views, instead of a full meal during their stay at school, adolescents prefer a snack; in connection with the irregular organization of the diet, adolescents 14-16 years old do not get the vital alimentary substances of animal and vegetable origin; the proposed bioactive
\end{abstract}

flour products will correct violations in the diet and will be in demand among adolescents 14-16 years old; the price increase for developed finished products compared to traditional does not go beyond the purchasing power of the target audience.

Keywords - school meals, flour products, alimentary shunting, bioactive additives

\section{INTRODUCTION}

In the modern world, food product lines aimed at specific consumer groups occupy an increasing place. In market conditions, an increasing place is given to attracting new natural sources of raw materials [1-5]. Due to the wide range of products, customers have become very picky and demanding on the quality of goods. This article is about school nutrition. According to the results of the monitoring of the Federal Service for Supervision of Consumer Rights Protection and Human Well-Being in Russia, it was found that in about $30 \%$ of modern schoolchildren, the cause of diseases (anemia, caries, stunted growth, and diseases of the gastrointestinal tract) is the unsatisfactory quality of school meals. If children of primary school age can be controlled to one degree or another, then the problem is more serious with adolescents. An increasing number of adolescents suffer from diseases caused by a lack of complete proteins, vitamins, macro- and microelements in the body [6-10]. 


\section{METHODS AND MATERIALS}

The objects of research were teenagers of 14-16 years old, studying in grades $8-10$, in secondary schools of the city of Voronezh in 2019. 368 teenagers took part in the experiment. An informed consent was obtained from the parents of the children to participate in the ongoing study of the child. The exclusion criteria were: age under 14 years old and over 16 years old; children absent at the time of the survey. In this study, a cross-sectional study was carried out simultaneously; the research program included a questionnaire (after the informed consent of the parents or guardians). The questionnaire developed by us included 3 blocks of 5 questions. The first block contained questions designed to disclose information about the diet of schoolchildren aged 14-16 and their attitude to school nutrition. The second block contained questions about the volume and composition of food consumed by respondents during the day. Answers to questions of the third block made it possible to give a tentative assessment of the demand for flour products of a functional orientation for the analyzed circle of people. After conducting the questionnaire, statistical data processing was performed using the Microsoft Office application package and Statistica 6.1.478 system for statistical data analysis [11-13].

The mathematical representation of calculating the optimal price level for fortified flour products can be calculated according to the following formula [14]:

$$
\begin{gathered}
C=L+S, \\
\alpha+\beta=\chi .(1)
\end{gathered}
$$

where $C$ - is the optimal price level for new functional products, rubles; $L$ - prices of products made according to the traditional recipe, rubles; $S$ - possible price increase based on the results of marketing research, rubles.

The functional dependence of the results of marketing research, which allows determining the potential market capacity, is presented below [14]:

$$
\begin{gathered}
F=C \cdot P \cdot W, \\
\alpha+\beta=\chi .
\end{gathered}
$$

where $F$ - potential market capacity, rubles; $C$ is the optimal price level for new functional products, rubles; $P$ - the number of people who regularly visit food service outlets and are loyal to products with functional additives (based on the results of marketing research), the number of units; $W$ - frequency of visits to food service outlets, number of days per month.

\section{RESULTS}

The purpose of the research was to analyze the marketing potential of flour products with a bioactive additive for feeding schoolchildren of adolescence, identifying the causes of violations of their diet.

According to the results of studies (Figure 1), it was found that $22 \%$ of adolescents eat in the school cafeteria, $7 \%$ - take food from home with them, the vast majority (56\%) - eat "from time to time", not observing the diet and $15 \%$ of people who are at school do not eat at all, while being in school for 5-8 hours a day.

Then the question arises: "How often do adolescents eat and do they follow a diet?" (Figure 2).

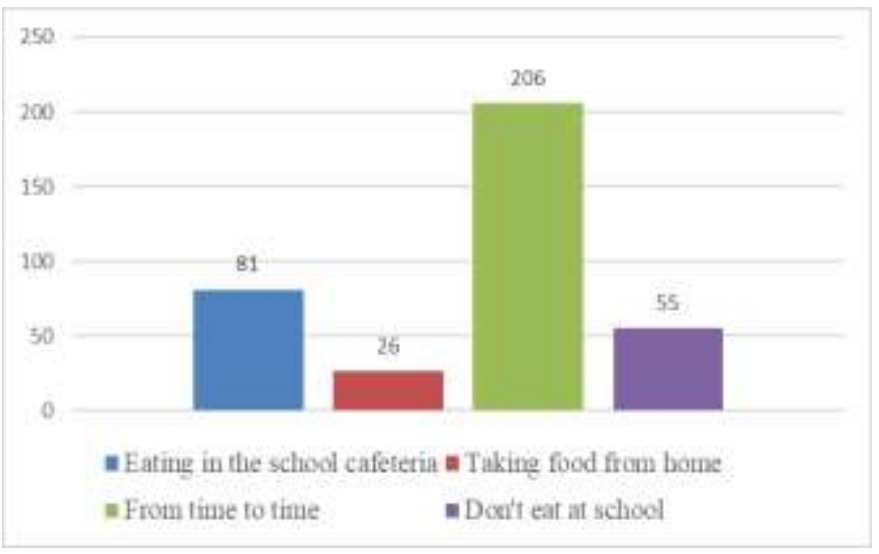

Fig. 1. Results of studies on respondents' eating preferences.

From the data in Figure 2 it follows that the majority (42\%) of schoolchildren take food no more than 2 times a day, usually it is breakfast, or a snack during the day and dinner; $21 \%$ of adolescents eat 3 times a day, $32 \%$ eat whenever possible and only $5 \%$ observe the correct diet. Moreover, the recommendations of dieticians prescribe 4-5 meals a day, which should consist of 3 main meals and 2-3 snacks [15-7].

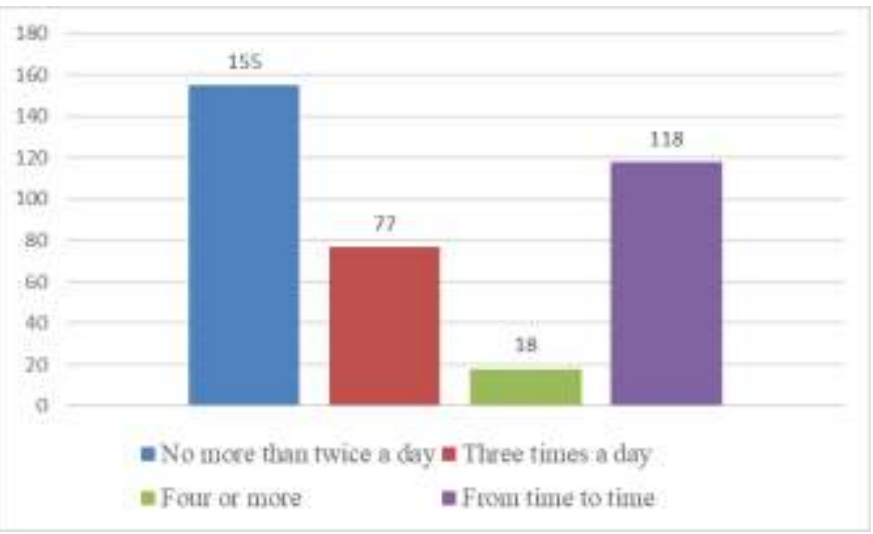

Fig. 2. The frequency of meals in students aged 14-16 years.

To the question: "Why do teenagers refuse to eat at school?" $31 \%$ of respondents cite the low organoleptic qualities of dishes offered in school canteens and buffets, $28 \%$ simply do not have time to have lunch, the reason for this is that some eat rather slowly, and in addition to eating, you have to stand a long line at lunch. The guys decide not to experience such inconvenience of eating at school and choose other methods of eating or completely refuse it. There is another equally significant problem that worries $27 \%$ of adolescents - constraint. The reason may be a whole range of reasons, one of them is the age-related features of the psyche at the age of 14-16, boys and girls are especially prone to maximalism, self-criticism, and exaggeration of their own 
shortcomings. Children are embarrassed to eat with their peers, motivating this by the fact that they are on a diet or do not experience a feeling of hunger (14\%). Suppressing hunger during the day, adolescents often develop concomitant diseases, gradually acquiring a chronic form.

The respondents were also asked about the quality of food products (Figure 3 ) sold on the school territory - $26 \%$ were completely satisfied with school meals, $40 \%$ were satisfied, but had a number of comments, and the rest $-34 \%$ were categorically not satisfied with the assortment they were offering. However, most teens still try to snack during the school day. The survey of respondents revealed the following data on the structure of their preferred assortment, which is possible for food on the school territory (Figure 4). Analyzing the data in Figure 4, we can conclude that today $67 \%$ of adolescents who are at school choose a snack consisting of any pastries, snacks or pastries as a meal. Only $8 \%$ of schoolchildren choose a complex lunch, which includes appetizer, soup, hot and drink, and $20 \%$ eat only soup or a second, and prefer to finish eating with a sweet dish. Only $5 \%$ of respondents find it difficult to answer, that is, the bulk of them are quite consciously eating at school.

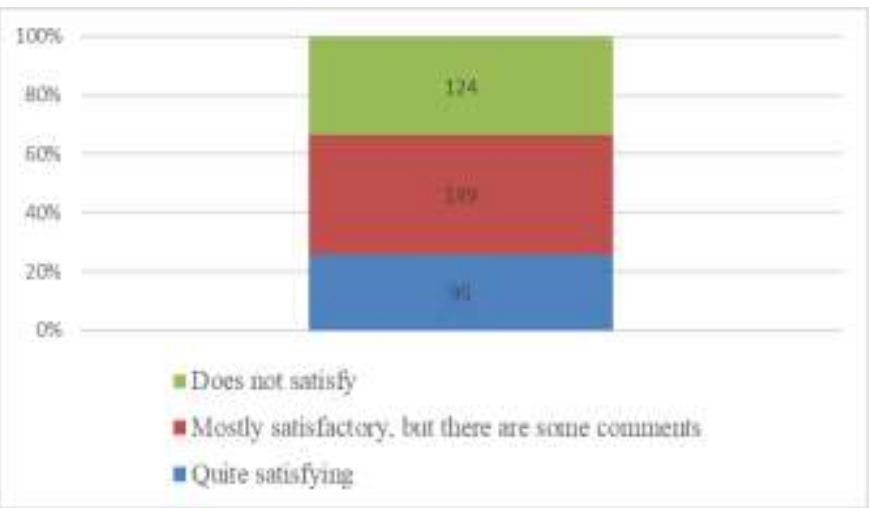

Fig. 3. The degree of satisfaction of adolescents with the range of food products offered at the school.

Further, in order to substantiate the recommendations on the consumption of flour confectionery products enriched with bioactive components, and the motivation for their purchase, the actual diet of schoolchildren aged 14-16 years was analyzed. The analysis of the survey on the presence of fruits and vegetables in the daily diet of respondents showed the following.
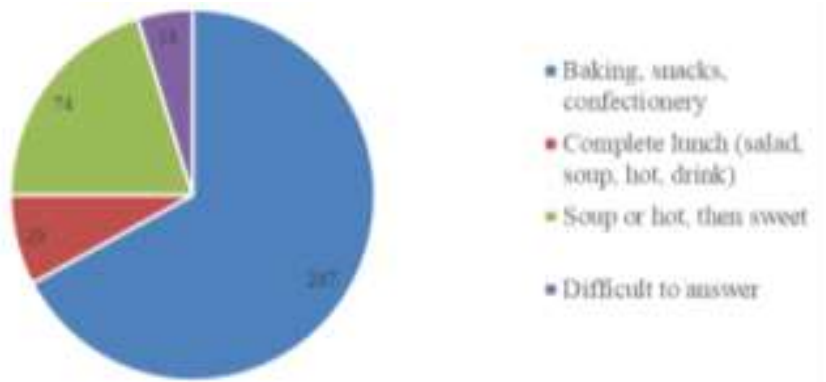

- Difficult to answer

Fig. 4. Preferences of teenagers in school nutrition.
The daily requirement for fruits and vegetables is fully satisfied only in $7 \%$ of adolescents; at the same time, in $24 \%$ it is partially satisfied - they consume fruits and vegetables, but in insufficient quantities; $47 \%$ - do not eat fruits and vegetables every day, therefore they lack them; $22 \%$ due to various reasons, practically do not include them in their diet

The daily need for dairy products is fully satisfied only in $6 \%$ of adolescents surveyed; $27 \%$ - consume dairy products less than the recommended norm; $65 \%$ - do not include this category of products in the daily diet, consuming them from time to time; $2 \%$ of adolescents categorically refuse products containing milk, rejection is mainly associated with various diseases (including lactose intolerance), personal beliefs (vegetarianism) and, in rare cases, taste preferences.

Summarizing the data on the use of eggs and products containing them, we can conclude that the majority of adolescents (99\% of respondents) consume them, of which $27 \%$ eat 5 eggs a week or more, therefore, they do not lack in this product; $38 \%$ eat less than 5 eggs a week and $34 \%$ eat foods containing eggs (in the form of various fillings and fillings) due to the mismatch of the organoleptic properties of this product with personal expectations.

Regarding meat and poultry, the results of the survey showed that only $30 \%$ of adolescents eat the daily intake recommended by dietitians; $41 \%$ - consumes meat or poultry daily, but not enough to meet daily requirements; $21 \%$-does not refuse meat products, but does not use them every day; $2 \%$ - completely refuse meat - the refusal is associated with vegetarians present among adolescents. With regard to fish and fish products, according to a survey of adolescents in sufficient quantities, fish is present in the diet of $14 \%$ of respondents; $48 \%$ - consume less than $420 \mathrm{~g}$ of fish per week; $37 \%$ - they eat fish very rarely, since this product in central Russia is quite expensive and not all families can afford it.

Due to the fact that the answer options in the questionnaire proposed to the respondents related to the complete rejection of a product contained a field "Mark the reason", we can conclude that rejection of animal products in most cases is due to the commitment of some adolescents to different types of vegetarianism. All over the world, in the age group of teenagers, especially among teenage girls, more and more rejections of meat occur, which threatens a certain danger to the health of these children. A mitigating moment can be considered that among the respondents a greater number of vegetarians belong to non-strict lacto-vegetarianism. This type of vegetarianism does not preclude the use of dairy products and eggs.

Summarizing the information about the actual diet of schoolchildren aged 14-16 (Table 1), we can conclude that modern adolescents are sorely lacking vitamins, macromicronutrients, amino acids, polyunsaturated fatty acids and other nutritional food factors, the suppliers of which are bioactive components of the animal and plant origin.

Given the preferences of adolescents who openly choose "empty" carbohydrate snacks (fast food, sandwiches, buns, cookies, sweets), we developed a component composition of a 
functional supplement for fortifying flour products, consisting of oilcake, animal albumin and alfalfa seeds.

Taking into account the current trends regarding products that make up the diet of adolescents, we analyzed the third block of the questionnaire, aimed at determining the demand for flour confectionery products enriched with a bioactive additive. First of all, the respondents were asked the question: "Have you heard anything about functional products?". The results showed that $44 \%$ of adolescents have an idea of this kind of products, of which $86 \%$ are girls. The difference between girls and boys' awareness is explained by the fact that girls are more concerned about issues of appearance and healthy eating. In turn, $77 \%$ of boys have never heard of the existence of functional products and have no idea about them.

TABLE I. DEFICIENCY OF PRODUCTS IN THE DIET OF ADOLESCENTS

\begin{tabular}{|l|c|}
\hline \multicolumn{1}{|c|}{ Product group } & $\begin{array}{c}\text { The number of adolescents experiencing } \\
\text { a shortage of products, \% }\end{array}$ \\
\hline Fruits and vegetables & 93 \\
\hline Dairy & 94 \\
\hline Eggs & 73 \\
\hline Meat and poultry & 70 \\
\hline Fish and seafood & 86 \\
\hline
\end{tabular}

It was previously established that the vast majority of respondents choose pastries and confectionery products presented in the snack format as a snack. Then the respondents were asked the question: "How do you motivate your choice of a snack?" And it turned out that $32 \%$ of the schoolchildren surveyed choose snack products, considering it convenient - a small, conveniently closed package that fits easily in your pocket, purse or school bag; $45 \%$ stop at this format due to the possibility of quick consumption of these products anywhere - at a break, without getting up from the school desk, in the corridor; $23 \%$ consider snack products tasty and satisfying (Figure 5).

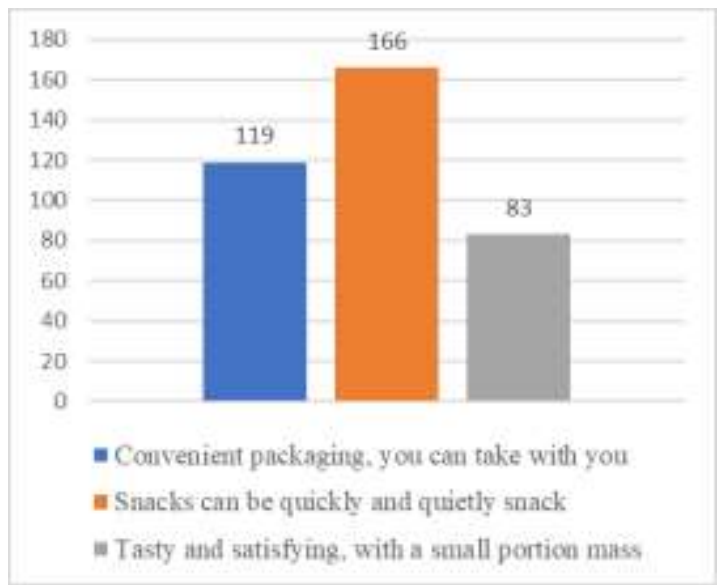

Fig. 5. Motivation for choosing snacks as a snack.
At the same time, to the question: "What reasons make you wary regarding functional products?", The majority of respondents $(62 \%)$ were afraid of a change in the organoleptic characteristics of the products traditionally known to them, most teenagers believe that "healthy can't be tasty" (Figure 6).

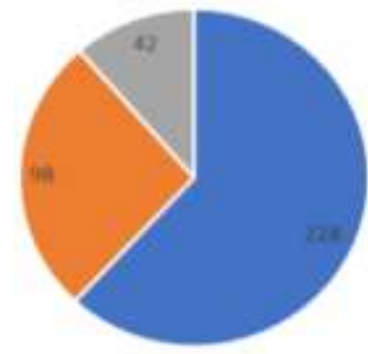

\section{- Charge in orgmoleptic indicators - Overpriced products * Difficult to anuwer}

Fig. 6. Doubts of adolescents regarding functional products.

Nevertheless, judging by the answers to the following question "Would you like useful snacks to appear in the school menu?", The guys are ready to experiment and try new ones (59\%); $27 \%$ of schoolchildren are afraid that the price of "healthy" snacks will be very high; the remaining $11 \%$ find it difficult to answer.

Further, in a simplified form, the respondents were asked the question: "Would you like useful snacks to appear on the school menu?", While $59 \%$ of respondents said they would prefer "useful" snacks; $12 \%$ were not sure about this; $29 \%-$ did not have a specific opinion (Figure 7).

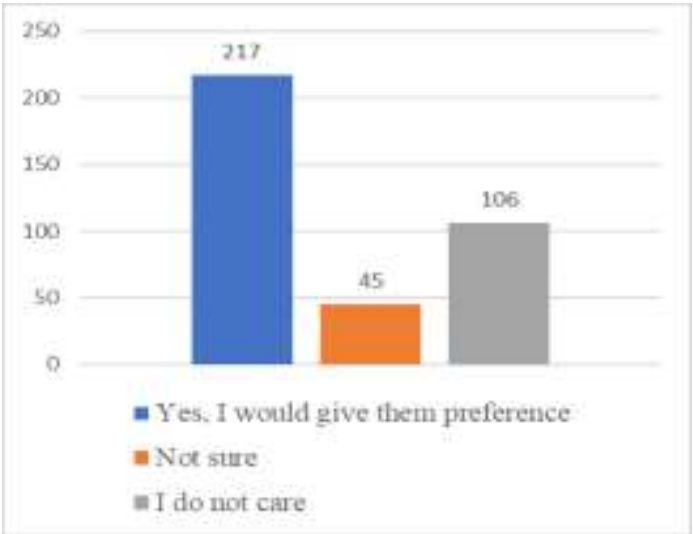

Fig. 7. Demand among teenagers fortified cookies.

When creating and promoting a functional product, it is important to understand that enriching its composition with alimentary components entails an increase in the cost of finished products. In connection with the increase in expenses for the production of finished goods, a further increase in prices for it is not reversible, since the profit of the enterprise directly depends on the size of the difference between revenue and expenses. To determine the purchasing power of the target audience, respondents were asked a reasonable question "How 
much money are you willing to spend on food at school every day?" (Figure 8). From Figure 8 it follows that $36 \%$ are willing to spend more than 120 rubles a day on food; $40 \%-$ stopped at average rates $-80-120$ rubles; $24 \%$ can afford a lunch or snack costing no more than 80 rubles a day.

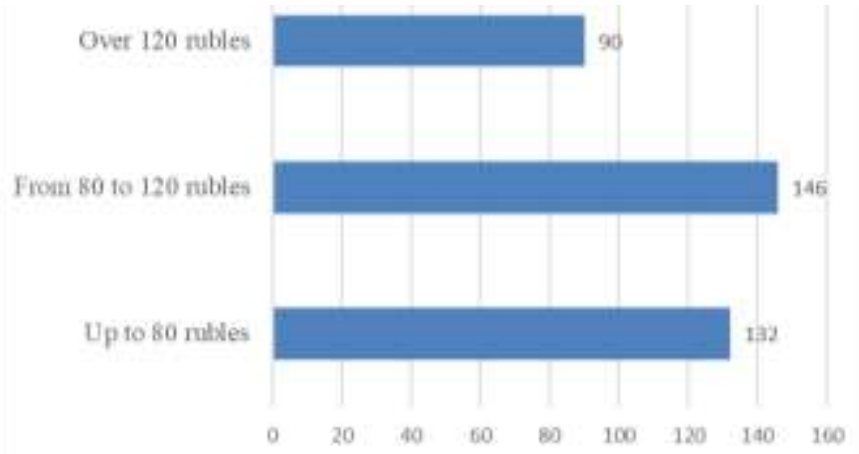

Fig. 8. Purchasing power of students aged $14-16$ years

The calculation (Formula 1) of the optimal price level for flour functional products with the developed bioactive additive showed that the range of retail prices for a unit of production will vary from 39 to 58 rubles per unit of production (a packet of cookies $100 \mathrm{~g}$ ).

When deciding on the release of a new product, it is also necessary to assess the potential market capacity. As a period for which an assessment of the potential market capacity was carried out, a month was chosen. The functional dependence of the results of marketing research, which allows determining the specified indicator, was calculated according to formula 2. As an assumption in the proposed model, the values obtained when answering the questions of marketing research that were selected by the maximum number of respondents were taken. The formula for determining the potential capacity is universal and the results may vary depending on the selected portions and formulations of the analyzed types of finished products. The formula is applicable in various regions. We give below the results of a marketing research on the components of a mathematical model of potential market capacity that can be used to analyze the effectiveness of a particular type of cookie with a developed enrichment additive. When analyzing the purchasing power of the target audience, it was revealed that the average price among $40 \%$ of respondents was $80-100$ rubles, for $26 \%$ of respondents $-100-120$ rubles. The remaining answer options were less popular in the course of the marketing research.

\section{CONCLUSION}

The study allows concluding that the use of an enriching additive for the production of bioactive flour products for school meals is cost-effective. Summarizing the data obtained during the study, we can draw the following conclusions: because of their age views, teenagers prefer a snack instead of a full meal during their stay at school; in connection with the irregular organization of the diet, adolescents 14-16 years old do not get the vital alimentary substances of animal and vegetable origin; the proposed bioactive flour products will correct violations in the diet and will be in demand among adolescents 14-16 years old; the price increase for developed finished products compared to traditional does not go beyond the purchasing power of the target audience.

\section{References}

[1] L. Antipova, N. Rodionova, E. Popov, "Development Trends in the Scientific Fundamentals of Food Design", News of higher ed. institut. Food Technol, vol. 1, pp. 8-11, 2018.

[2] T. Nekrasova, "The problems of optimization the quality of life in modern Russia through the prism of economic theory and practic", Proc. of the Voronezh State Univer. of Engineer. Technol., vol. 3, pp. 386-391, 2018.

[3] Y. Kolomnikova, A. Derkanosova, M. Manukovskaya, "The influence of non-traditional plant materials on biotechnological properties and the structure of butter dough", Proc. of the Voronezh State Univer. of Engineer. Technol., vol. 3, pp. 157-160, 2015.

[4] A. Simonenkova, E. Sergeeva, A. Shilov, E. Artemova. "The rationale for the use of lentil protein dispersion in the technology of curd products", Natural and techn. Sci., vol. 11, pp. 79-85, 2018.

[5] E. Artemova, K. Vlasova, O. Zvyagina, "Prospects for the use of pumpkin seed flour in the technology of semi-finished products from poultry", Technol. and commodity sci. of innovat. food products, vol. 3, pp. 14-18, 2019.

[6] T. Alekseeva, Y. Kalgina, A. Vesnina, "Development of an assortment of flour confectionery products of high nutritional value for children of senior school age", Econ. Innovat. Quality control, vol. 1, pp. 228-229, 2015 .

[7] N. Berezina, E. Khmeleva, E. Artemova, "Modeling a multicomposite mixture of vegetable powders for bakery products", Bread products, vol. 6, pp. 44-47, 2019.

[8] T. Alekseeva, Y. Kalgina, A. Fursova, "Prospects for the use of products of deep processing of domestic raw materials in diets of a medical and preventive orientation", Commodity expert on food products, vol. 9, pp. 69-74, 2019.

[9] N. Tapeshkina, T. Egorenko, "Results of a hygienic assessment of school breakfasts", Nutrition for children and adolescents, vol. 1, pp. 27-29, 2016.

[10] G. Magomedov, N. Zatsepilina, Y. Slepokurova, "Economic and social aspects of the development of innovative technologies in the field of school food industry", Technol. of food and process. industry of the agro-industrial complex - healthy food products,vol. 4, pp. 90-95, 2015.

[11] A. Skrypnikov, E. Belokurova, N. Sotnikov, "Mathematical modeling of the interaction of functional and contaminating microorganisms in a biotechnological system", Proc. of the Voronezh State Univer. of Engineer. Technol., vol. 1, pp. 252-255, 2019.

[12] A. Alekseev, G. Abramov, I. Bulgakova, "Model for evaluating the effectiveness of methods for eliminating the risks of functioning complex systems", Bull. of Voronezh State Univer.,vol. 1, pp. 13-20, 2019.

[13] G. Abramov, A. Gavrilov, "Modeling of carbon nanostructures synthesis in low-temperature plasma", Advan. Mater. and Technol., vol. 1, pp. 21-34, 2019

[14] R. Omarov, O. Sycheva, Basics of rational nutrition. Stavropol: Stavropol State Agrar. Univer., 2016.

[15] E. Ambrosieva, Physiology of Nutrition. Moscow: Knigorus, 2018.

[16] D. Edelev, N. Labutina, "Aspects of healthy eating for schoolchildren", Nutrition and health, vol. 11.pp. 64-66, 2014.

[17] D. Alexandrov, G. Poryadina, "Features of the eating behavior of children and adolescents in large cities", Nutrition, vol. 4. pp. 67-74, 2014. 